University of Nebraska - Lincoln

DigitalCommons@University of Nebraska - Lincoln

Publications, Agencies and Staff of the U.S.

Department of Commerce

U.S. Department of Commerce

2006

\title{
Differential Expression of Immune Response Genes in Steller Sea Lions (Eumetopias jubatus): An Indicator of Ecosystem Health?
}

\author{
Lizabeth Bowen \\ University of California, Davis \\ Brian Aldridge \\ University of California, Davis \\ Kimberlee Beckmen \\ Alaska Department of Fish and Game \\ Tom Gelatt \\ National Marine Fisheries Service, Alaska Fisheries Science Center/NMML \\ Lorrie Rea \\ Alaska Department of Fish and Game \\ See next page for additional authors \\ Follow this and additional works at: https://digitalcommons.unl.edu/usdeptcommercepub \\ Part of the Environmental Health Commons, Environmental Indicators and Impact Assessment \\ Commons, Marine Biology Commons, Other Immunology and Infectious Disease Commons, Other \\ Oceanography and Atmospheric Sciences and Meteorology Commons, and the Zoology Commons
}

Bowen, Lizabeth; Aldridge, Brian; Beckmen, Kimberlee; Gelatt, Tom; Rea, Lorrie; Burek, Kathy; Pitcher, Ken; and Stott, Jeffrey L., "Differential Expression of Immune Response Genes in Steller Sea Lions (Eumetopias jubatus): An Indicator of Ecosystem Health?" (2006). Publications, Agencies and Staff of the U.S. Department of Commerce. 204.

https://digitalcommons.unl.edu/usdeptcommercepub/204

This Article is brought to you for free and open access by the U.S. Department of Commerce at DigitalCommons@University of Nebraska - Lincoln. It has been accepted for inclusion in Publications, Agencies and Staff of the U.S. Department of Commerce by an authorized administrator of DigitalCommons@University of Nebraska - Lincoln. 


\section{Authors}

Lizabeth Bowen, Brian Aldridge, Kimberlee Beckmen, Tom Gelatt, Lorrie Rea, Kathy Burek, Ken Pitcher, and Jeffrey L. Stott 


\title{
Differential Expression of Immune Response Genes in Steller Sea Lions (Eumetopias jubatus): An Indicator of Ecosystem Health?
}

\author{
Lizabeth Bowen, ${ }^{1}$ Brian Aldridge, ${ }_{1}^{1,2}$ Kimberlee Beckmen, ${ }^{3}$ Tom Gelatt, ${ }^{4}$ Lorrie Rea, ${ }^{3}$ Kathy Burek, ${ }^{5}$ \\ Ken Pitcher, ${ }^{3}$ and Jeffrey L. Stott ${ }^{1}$ \\ ${ }^{1}$ Laboratory for Marine Mammal Immunology, School of Veterinary Medicine, Department of Pathology, Microbiology and Immunology, \\ University of California at Davis, 1 Shields Avenue, Davis, CA 95616 \\ ${ }^{2}$ Department of Veterinary Clinical Sciences, The Royal Veterinary College, The University of London, Hertfordshire AL9 7TA, UK \\ ${ }^{3}$ Division of Wildlife Conservation, Marine Mammals Section, Alaska Department of Fish and Game, Fairbanks, AK \\ ${ }^{4}$ National Marine Fisheries Service, Alaska Fisheries Science Center/NMML, Seattle, WA \\ ${ }^{5}$ Alaska Veterinary Pathology Services, Eagle River, AK
}

\begin{abstract}
Characterization of the polygenic and polymorphic features of the Steller sea lion major histocompatibility complex (MHC) provides an ideal window for evaluating immunologic vigor of the population and identifying emergence of new genotypes that reflect ecosystem pressures. MHC genotyping can be used to measure the potential immunologic vigor of a population. However, since ecosystem-induced changes to MHC genotype can be slow to emerge, measurement of differential expression of these genes can potentially provide real-time evidence of immunologic perturbations. MHC DRB genes were cloned and sequenced using peripheral blood mononuclear leukocytes derived from 10 Steller sea lions from Southeast Alaska, Prince William Sound, and the Aleutian Islands. Nine unique DRB gene sequences were represented in each of 10 animals. MHC DRB gene expression was measured in a subset of six sea lions. Although DRB in genomic DNA was identical in all individuals, relative levels of expressed DRB mRNA was highly variable. Selective suppression of MHC DRB genes could be indicative of geographically disparate environmental pressures, thereby serving as an immediate and sensitive indicator of population and ecosystem health.
\end{abstract}

Key words: Steller sea lion, ecosystem health

The polygenic and polymorphic attributes of the major histocompatibility complex (MHC) are proposed to be central to maintaining the immunologic health and vigor of a species. MHC genes encode a set of transmembrane proteins critical to the generation of immune responses (Paul, 1999; Klein and Sato, 2000a,b). The variety of MHC-

Published online: June 9, 2006

Correspondence to: Lizabeth Bowen, e-mail: lbowen@ucdavis.edu encoded proteins in an individual ultimately determines the repertoire of foreign peptides to which that animal is capable of responding and, at the population level, reflects the historic influence of pathogen pressures and breeding biology (Zinkernagel, 1979; Reizis et al., 1998). This MHC genetic diversity plays an important role in a host's ability to accommodate rapidly evolving infectious agents that periodically afflict natural populations (Yuhki and O'Brien, 1990). To date, MHC diversity has been delineated using 
genomic analysis. Such MHC genotyping has facilitated identification of individuals and/or populations with low levels of immunogenetic heterogeneity and attempted to associate this with both past pathogenic and environmental influences (Hedrick, 1994; Hughes and Hughes, 1995) and increased susceptibility to novel environmental insults.

Examination of the MHC provides an ideal window for evaluating the immunologic vigor of populations. However, the environment to which the Steller sea lions are currently exposed is changing relative to that in which the MHC evolved. Expression of these MHC genes is similarly influenced by environmental change and has the added benefit of reflecting real-time insults. Extensive literature has established relationships between physiologic insults (including environmental contaminants/chemicals, viruses, and nutritional stress) and reduced MHC class II expression (Snyder and Unanue, 1982; Hughes et al., 1996; Dong et al., 1997; Venkatraman and Pendergast, 2002; Schwab et al., 2005). Thus, extension of the genotyping approach, to include quantitative measurement of transcription of individual MHC genes, should provide a timely and relevant measure of altered host immune potential and environmental stress. In light of this concept, we developed a quantitative PCR system to examine MHC class II DRB gene expression in Alaskan Steller sea lions (SSL; Eumetopias jubatus) from two genetically distinct populations, the threatened Eastern and endangered Western stocks.

Ten SSLs ranging in age from 2 months to 2 years old were sampled from Prince William Sound (PWS), Southeast Alaska (SE), and the Aleutian Islands (AL). Caudal gluteal venous blood samples were collected into the anticoagulant, ethylenediaminetetraacetic acid (EDTA Vacutainer $^{\circledR}$ CPT $^{\mathrm{TM}}$; Becton Dickinson, Franklin, NJ) for isolation of peripheral blood leukocytes (PBLs) (Bowen et al., 2004). Extraction of DNA and RNA from PBLs was performed according to methods in Bowen et al. (2004, 2005).

A primer pair recognizing the flanking regions of the putative peptide-binding site (based upon sequence data from the closely-related California sea lion (CSL; Zalophus californianus) DRBURN and DRBlociR) was used to amplify SSL (Euju)-DRB exon 2 and the preceding intron (Table 1). PCR amplifications using these class II primers were performed on $20 \mathrm{ng}$ of each SSL DNA using protocols described in Bowen et al. (2004). The PCR was performed on an MJ Research PTC-200 thermal cycler (MJ Research, Watertown, MA) and consisted of five cycles at $94^{\circ} \mathrm{C}$ for 30 seconds, 30 cycles at $60^{\circ} \mathrm{C}$ for 30 seconds, and $72^{\circ} \mathrm{C}$ for 2
Table 1. Primer Pairs for Quantification of Steller Sea Lion MHC DRB

\begin{tabular}{ll}
\hline Name & Primer sequence \\
\hline ZCDRBURN & CCCTCCCTTGGCTTGGGCTAG \\
ZCDRBLEX23 & GTAGGCTCAACTCGCCGCTGC \\
DRBlociR & CTCGCCGCTGCRCCRKGAAG \\
DRBDNAintron & GGATSSTTCGTGTCCCCACAG \\
ZCDRB194A & TCATTTCTTGGAGCTGTTGAAGGG \\
ZCDRB194B & TCATTTCTTGCTCCTGTTTAAGG \\
ZCDRB194C & TCATTTCTTGGAGCTGTTGAAGGC \\
ZCDRB194D & TCATTTCTTGCTCCTGTGTAAGTC \\
ZCDRB194E & TCATTTCTTGCACCTGTGTAAGGC \\
ZCDRB194F & TCATTTCTTGCACCTGTTTAAGGC \\
ZCDRB194G & TCATTTCTTGGAGCTGTTTAAGGC \\
ZCDRB194H & TCATTTCTTGCTCCTGTGTAAGGC \\
ZCDRB194J & TCATTTCTTGCTCCTGTGTAAGGG \\
EujuS9F & AGATGAAGCTGGATTACATCCTGGG \\
EujuS9R & CTTCCTCTTCACACGGCCTGGGC
\end{tabular}

minutes, ending with an extension step of $72^{\circ} \mathrm{C}$ for 10 minutes. The products of these reactions were electrophoresed on $1.5 \%$ agarose gels and visualized by ethidium bromide staining. Bands representing PCR products of the predicted size were excised from the gel, extracted, purified, cloned, and sequenced (Bowen et al., 2004). Nucleotide sequences of the amplicons were analyzed using Align $^{\mathrm{TM}}$ and Contig ${ }^{\mathrm{TM}}$ sequence alignment software programs (Vector NTI ${ }^{\mathrm{TM}}$, Informax Inc, North Bethesda, MD). Based upon these sequences, a new forward primer, located in the intron preceding exon 2, was designed (DRBDNAintron) (Table 1). Subsequent PCR reactions were performed using the primer pair (DRBDNAintron and DRB lociR) on SSL DNA using the conditions described above. Cloning and sequencing were performed to characterize Euju-DRB loci.

Reverse transcription was performed on RNA samples from six Steller sea lions according to protocols in Bowen et al. (2004). Based upon data gained from cloning and sequencing $E u j u-D R B$, we were able to use eight sequencespecific primer (SSP) pairs previously designed for CSL and one newly identified SSP Euju-DRB.J in combination with DRBlociR (Table 1) (Bowen et al., 2004). Genomic DNA from each animal was analyzed with all nine SSPs using an intercalating fluorescent dye PCR (Bowen et al., 2004). Amplifications were performed in an iCycler (BioRad, Hercules, CA) under the following conditions: 2 minutes at $50^{\circ} \mathrm{C}$, followed by 15 minutes at $95^{\circ} \mathrm{C}$, and 35 cycles of $94^{\circ} \mathrm{C}$ for 30 seconds, $58^{\circ} \mathrm{C}$ for 30 seconds, and 
Table 2. Relative Expression Levels of Euju-DRB.A-Euju-DRB.J in Six Steller Sea Lions from Southeast Alaska, Prince William Sound, and the Aleutian Islands ${ }^{\mathrm{a}}$

\begin{tabular}{llllllllllll}
\hline & Age (months) & Sex & A & B & C & D & E & F & G & H & J \\
\hline SSL 056 SE & 2 & F & 89,579 & 0 & 1575 & 1 & 177 & 109 & 7 & 408 & 0 \\
SSL 140 SE & 14 & F & 113,477 & 0 & 3112 & 3 & 306 & 95 & 9 & 497 & 0 \\
SSL 065 SE & 7 & M & 212,927 & 10,086 & 28,399 & 3 & 11,900 & 49,778 & 16 & 1890 & 0 \\
SSL 090 PWS & 23 & F & 152 & 1 & 131,387 & 2 & 482 & 249 & 210,719 & 672 & 0 \\
SSL 302 AL & 9 & M & 0 & 27,645 & 49,667 & 0 & 36,419 & 99,334 & 198,668 & 3216 & 0 \\
SSL 263 AL & 15 & M & 102 & 7149 & 67,888 & 3 & 778 & 286 & 136,428 & 5051 & 57,926 \\
& & & & & & & & & & &
\end{tabular}

SSL, Steller sea lions; SE, Southeast Alaska; PWS, Prince William Sound; AL, Aleutian Islands.

${ }^{\mathrm{a}}$ Determined by $2^{-\triangle \Delta \mathrm{CT}}$ method.

$72^{\circ} \mathrm{C}$ for 30 seconds, with a final extension step of $72^{\circ} \mathrm{C}$ for 10 minutes. Reaction specificity was monitored by melting curve analysis using a final data acquisition phase of 60 cycles of $65^{\circ} \mathrm{C}$ for 30 seconds and verified by direct sequencing of randomly selected amplicons (Bowen et al., 2004).

cDNA was examined with all nine SSL SSPs and a control gene, ribosomal subunit S9 SSP (Table 1). Quantitative PCR systems for SSL S9 and MHC genes were conducted in individual wells. Each reaction contained 500 ng DNA in $25 \mu \mathrm{l}$ volumes with $20 \mathrm{pmol}$ SSP, 20 pmol DRBLex23, Tris-Cl, $\mathrm{KCl},\left(\mathrm{NH}_{4}\right)_{2} \mathrm{SO}_{4}, 2.5 \mathrm{mM} \mathrm{MgCl} 2$ (pH 8.7), dNTPs, HotStar Taq DNA Polymerase (Quantitect SYBR Green PCR Master Mix, Qiagen, Valencia, CA), and 0.5 units uracil-N-glycosylase (Roche, Indianapolis, IN). Amplifications were performed in an iCycler (BioRad) under the following conditions; 2 minutes at $50^{\circ} \mathrm{C}$, followed by 15 minutes at $95^{\circ} \mathrm{C}$, and 35 cycles at $94^{\circ} \mathrm{C}$ for 30 seconds, $58^{\circ} \mathrm{C}$ for 30 seconds, and $72^{\circ} \mathrm{C}$ for 30 seconds, with a final extension step of $72^{\circ} \mathrm{C}$ for 10 minutes. Reaction specificity was monitored by melting curve analysis using a final data acquisition phase of 60 cycles at $65^{\circ} \mathrm{C}$ for 30 seconds and verified by direct sequencing of randomly selected amplicons. Additionally, expression levels of all nine SSL $D R B$ gene sequences were established from six Steller sea lions.

RNA preparations, with and without prior DNase treatment and with or without RT-step, were subjected to quantitative PCR to confirm the absence of contaminating gDNA. None of the PCR systems produced a signal when DNase treated $\mathrm{RT}^{-}$RNA samples were used for the amplification.

PCR products of the target genes and S9 were randomly chosen for sequencing to verify analytical specificity using standard sequencing procedures (ABI 377 DNA sequencer).

Data were expressed relative to a reference sample, called the calibrator (weakest signal), for relative quantitation by the comparative $\mathrm{C}_{\mathrm{T}}$ method. The $\mathrm{C}_{\mathrm{T}}$ for the target amplicon and the $\mathrm{C}_{\mathrm{T}}$ for the endogenous control were determined for each sample. Differences in the $\mathrm{C}_{\mathrm{T}}$ for the target and the $\mathrm{C}_{\mathrm{T}}$ for the endogenous control $\left(\Delta \mathrm{C}_{\mathrm{T}}\right)$ were calculated to normalize for differences in RNA extractions and efficiency of the RT step. The $\Delta \mathrm{C}_{\mathrm{T}}$ for each experimental sample was subtracted from the $\Delta \mathrm{C}_{\mathrm{T}}$ of the calibrator resulting in a $\Delta \Delta \mathrm{C}_{\mathrm{T}}$ value. Lastly, the amount of target, normalized to the endogenous control and relative to the calibrator, was calculated by $2^{-\Delta \Delta C T}$. Thus, all experimental samples are expressed as an $n$-fold difference relative to the calibrator (Leutenegger et al., 1999).

Examination of genomic DNA from 10 SSLs revealed the presence of nine MHC DRB sequence patterns, all being present in each individual. The lack of sequence configuration differences among these 10 individuals is in contrast to the wide range of MHC DRB sequence configurations recently described within populations and rookeries of CSLs (Bowen et al., 2004, 2005).

Identification of real-time pressure on the SSL immune system, not yet reflected at the genomic level, was identified by quantitation of mRNA encoded by each individual MHC DRB gene. Extensive variation in the expression of MHC DRB genes was identified (Table 2). Although present in the genomic DNA, select Euju-DRB genes were either relatively reduced in expression or completely absent (Table 2). Only one animal (AL) expressed all nine Euju$D R B$ genes. Euju-DRB.A and .G were both differentially expressed with three animals expressing relatively less of $D R B . A$ and the other three expressing relatively less of 
DRB.G. Euju-DRB.B was not expressed in two of the three SE animals, DRB.D was not expressed in one of the AL animals, and DRB.J was not expressed in five of the six animals.

Retrospective studies have suggested that population bottlenecks, resulting in loss of genetic diversity within the MHC gene complex, have precipitated an increased susceptibility to emerging infectious diseases (Yuhki and O’Brien, 1990; Hedrick, 1994; Hughes and Hughes, 1995). The current study presents a unique approach to complement classic genotyping data by providing real-time assessment of perturbations in these functionally relevant MHC genes. Expression of MHC class II genes is highly regulated at the level of gene transcription by multiple factors. While limited studies have suggested that control of select MHC genes can be differentially regulated through promoter polymorphism (Andersen et al., 1991; Berggren and Seddon, 2005), extensive literature has established relationships between physiologic insults and reduced MHC class II expression (Snyder and Unanue, 1982; Schwab et al., 2005). The rationale for our approach was supported by the demonstration that environmental contaminants/chemicals and nutritional stress can result in suppression of the expression (gene transcription) of select MHC genes (Hughes et al., 1996; Dong et al., 1997; Venkatraman and Pendergast, 2002). The utility of this approach is in its ability to provide a more timely indicator of changes in ecosystem health.

While the numbers of animals examined in this study are extremely limited, the demonstration of differential MHC gene expression in animals from geographically disparate regions is intriguing. The Southeast Alaska population has been increasing for a long period of time, perhaps the past 90 years or so. The Prince William Sound subpopulation has been relatively stable since about 1975, while the Aleutian subpopulation has declined by perhaps 80\%-90\% since about 1975 (Trites and Larkin, 1996).

These preliminary findings appear to suggest MHC gene expression in marine mammals might be useful as an early warning indicator of environmental stress and ecosystem degradation (Tabor and Aguirre, 2004). However, to demonstrate that the variation in MHC is meaningful in this regard, further research is needed to establish statistically consistent patterns within static populations, and differences between populations within unique environments. This would be most effectively realized through the temporal analysis of captive sea lions living in controlled environments.

\section{ACKNOWLEDGMENTS}

We gratefully acknowledge the constructive suggestions offered by the editor. This research was funded in part by the Alaskan Department of Fish and Game (through NMFS co-operative agreement NA17FX1079) and a UC Davis Faculty Research Grant. Samples were collected under US Marine Mammal Protection Act and Endangered Species Act permits \#965 and 358-1564.

\section{REFERENCES}

Andersen LC, Beaty JS, Nettles JW, Seyfried CE, Nepom GT, Nepom BS (1991) Allelic polymorphism in transcriptional regulatory regions of HLA-DQB genes. Journal of Experimental Medicine 173:181-192

Berggren KT, Seddon JM (2005) MHC promoter polymorphism in grey wolves and domestic dogs. Immunogenetics [Online]

Bowen L, Aldridge BM, Gulland FMD, et al. (2004) Class II multiformity generated by variable MHC-DRB region configurations in the California sea lion (Zalophus californianus). Immunogenetics 56:12-27

Bowen L, Aldridge BM, DeLong R, Melin S, Buckles EL, Gulland F, et al. (2005) An immunogenetic basis for the high prevalence of urogenital cancer in a free-ranging population of California sea lions (Zalophus californianus). Immunogenetics 56:846-848

Dong L, Ma Q, Whitlock JP Jr (1997) Down-regulation of major histocompatibility complex Q1b gene expression by 2,3,7,8tetrachlorodibenzo-p-dioxin. Journal of Biological Chemistry 272:29614-29619

Fox GA (2001) Wildlife as sentinels of human health effects in the Great Lakes-St. Lawrence basin. Environmental Health Perspectives 109(Suppl 6):853-861

Hedrick PW (1994) Evolutionary genetics of the major histocompatibility complex. American Naturalist 143:945-964

Hughes AL, Hughes MK (1995) Natural selection on the peptidebinding regions of major histocompatibility complex molecules. Immunogenetics 42:233-243

Hughes DA, Pinder AC, Piper Z, Johnson IT, Lund EK (1996) Fish oil supplementation inhibits the expression of major histocompatibility complex class II molecules and adhesion molecules on human monocytes. American Journal of Clinical Nutrition 63:267-272

Klein J, Sato A (2000a) The HLA system: first of two parts. New England Journal of Medicine 343:702-709

Klein J, Sato A (2000b) The HLA system: second of two parts. New England Journal of Medicine 343:782-786

Leutenegger CM, Mislin CN, Sigrist B, Ehrengruber MU, Hofmann-Lehmann R, Lutz H (1999) Quantitative real-time PCR for the measurement of feline cytokine mRNA. Veterinary Immunology and Immunopathology 71:291-305

Paul WE (1999) Fundamental Immunology, 4th ed., Philadelphia: Lippincott-Raven, xxi, $1589 \mathrm{pp}$

Reizis B, Eisenstein M, Mor F, Cohen IR (1998) The peptidebinding strategy of the MHC class II I-A molecules. Immunology Today 19:212-216 
Rimsza LM, Roberts RA, Miller TP, Unger JM, LeBlanc M, Braziel $\mathrm{RM}$, et al. (2004) Loss of MHC class II gene and protein expression in diffuse large B-cell lymphoma is related to decreased tumor immunosurveillance and poor patient survival regardless of other prognostic factors: a follow-up study from the Leukemia and Lymphoma Molecular Profiling Project. Blood 103:4251-4258

Schwab CL, Fan R, Zheng Q, Myers P, Hebert P, Pruett SB (2005) Modeling and predicting stress-induced immunosuppression in mice using blood parameters. Toxicological Sciences 83:101-113

Snyder DS, Unanue ER (1982) Corticosteroids inhibit murine macrophage 1a expression and interleukin 1 production. Journal of Immunology 129:1803-1805

Tabor GM, Aguirre AA (2004) Ecosystem health and sentinel species: adding an ecological element to the proverbial "canary in the mineshaft." EcoHealth 1:226-228
Trites AW, Larkin PA (1996) Changes in the abundance of Steller sea lions (Eumetopias jubatus) in Alaska from 1956 to 1992: how many were there? Aquatic Mammals 22:153-166

Venkatraman JT, Pendergast DR (2002) Effect of dietary intake on immune function in athletes. Sports Medicine 32:323-337

Youn J, Lynes MA (1999) Metallothionein-induced suppression of cytotoxic T lymphocyte function is an important immunoregulatory control. Toxicological Sciences 52:199-208

Yuhki N, O’Brien SJ (1990) DNA variation of the mammalian major histocompatibility complex reflects genomic diversity and population history. Proceedings of the National Academy of Sciences 87:836-840

Zinkernagel RM (1979) Associations between major histocompatibility antigens and susceptibility to disease. Annual Review of Microbiology 33:201-213 